\title{
Lead-210 dating of sediments compared with accumulation rates estimated by natural markers and measured with sediment traps
}

\author{
J. Bloesch ${ }^{1}$ \& R. D. Evans ${ }^{2}$ \\ ${ }^{1}$ Limnological Department, EAWAG, CH-8600 Dübendorf, Switzerland \\ 2 Trent University, Peterborough, Qntario K9J 7B8, Canada
}

Keywords: lead-210 dating, natural sediment marker, sediment traps, sediment accumulation

\begin{abstract}
Methods to provide accurate accumulation rates for lake models are discussed. Cores were taken in 1979 in two basins of Lake Lucerne, Switzerland, and accumulation rates were calculated by using $\mathrm{Pb}-210$ dating and by a natural landslide marker of 1795 in one basin (Weggis). In the other basin (Horw Bay) the sediment accumulation rates based on the lead method were compared with yearly sedimentation rates measured by sediment traps in 1969/70. At the Weggis station, the core dating yielded sediment accumulation rates of about $400 \mathrm{~g}$ dry wt. $\mathrm{m}^{-2} \mathrm{y}^{-1}$ with the lead method, averaged over a sediment depth of $4-20 \mathrm{~cm}$; accumulation was about $700 \mathrm{~g}$ dry wt. $\mathrm{m}^{-2} \mathrm{y}^{-1}$ with the marker method, averaged over 0-33 $\mathrm{cm}$. In Horw Bay, the trap method yield'd about $1300 \mathrm{~g}$ dry wt. $\mathrm{m}^{-2} \mathrm{y}^{-1}$ compared with $400-1000 \mathrm{~g}$ dry wt. $\mathrm{m}^{-2} \mathrm{y}^{-1}$ obtained with the lead method and related to various depth intervals. The characteristic sources of error of the three methods as well as several hypotheses for these discrepancies are discussed.
\end{abstract}

\section{Introduction}

In an effort to model expected changes in lake water quality resulting from stress or restoration, a mass balance approach has often been used (Vollenweider 1975; Dillon \& Rigler 1974; Imboden \& Gächter 1979). Despite the great strengths of this approach to lake modelling, it requires quantification of fluxes to and from compartments such as the sediment input and release. These are not always readily and accurately measurable, and thus field data have been quite often replaced by general assumptions (e.g. Imboden \& Lerman 1978). It is obvious, however, that a model for a case study can be considerably improved if exact field data are at hand.

Various methods, which can be grouped into two categories, have been proposed for measuring sedimentation and sediment accumulation: 1) collection of settling material by sediment traps; and 2) measurement of accumulated material by different core dating procedures. Although these measurements are not likely the same, there is no information in the literature to suggest which of them is the most appropriate to mass balance studies.

Collection of settling material is normally accomplished through the use of sediment traps. Gardner (1980) and Hargrave \& Burns (1979) have demonstrated the validity of sediment traps in efficiency tests, and Bloesch \& Burns (1980) have reviewed the related problems of this method which are mainly mineralization within the traps and interference by bottom resuspension. Pennington (1974) compared the trap method with core dating by different markers as well as Cs-137 and Pb-210. The agreement was reasonably good, but her measurements were made in depth units instead of mass units. The former can hide differences in mass accumulation due to compaction, and it is the mass accumulation which is of concern in mass balance modelling. Similar positive results from comparative investigations have been reported by Serruya

Hydrobiologia 92, 579-586 (1982). 0018-8158/82/0922-0579/\$01.60.

๑ Dr W. Junk Publishers, The Hague. Printed in The Netherlands. 
(1977), Bloesch (1974) vs. Bloesch (1977) and Staub (1977), and by Ravera \& Viola (1977). In contrast, sediment trap collections of phosphorus overestimated phosphorus retention (input minus output) by ten times in two other studies (Fuhs 1973; Nicholls 1977). Although such discrepancies may be explained by recycling processes there is no certainty that sediment trap collections are a valid input to mass balance studies and they have not yet been adequately tested. Further, it is difficult to relate load calculations to such field measurements.

Usually a dating technique (such as Pb-210, Cs137, Ambrosia horizon, etc.) is employed in the measurement of sediment accumulation. Because of the phenomenon of sediment focusing, however, and in order to avoid overestimation, sediment accumulation must be measured at a number of locations and integrated over the whole lake area before an appropriate value for mass balance studies can be arrived at (Kipphut 1979). Evans \& Rigler (1980) used lead-210 dating at a series of locations in Bob Lake and found good agreement between sediment phosphorus accumulation and a previous mass balance study. Evans (1980) found similar good agreement in two other lakes. However, with such limited evidence there is, as yet, no clear proof that sediment accumulation measurements are appropriate to mass balance studies.

In our study, lead- 210 dating has been chosen as the method of measuring sediment accumulation. The validity of lead-210 dating is generally accepted (Robbins 1978; Eakins \& Morrison 1978), but it has not received as much testing as one might wish before choosing it as a standard, against which to compare other techniques. For this reason, we have compared the results of lead-210 dating to a landslide marker (Staub 1977) in Lake Lucerne, Switzerland. With this reference, we can estimate the validity of the lead-210 dating method before comparing sediment trap and lead- 210 sediment accumulation at another location of the lake, where no landslide occurred.

Thus, the purpose of this paper is to interpret possible differences between measurements by sediment trap and two sediment dating methods, and to determine whether either or both categories of measurement are suitable for use in mass balance studies.

\section{Methods}

Three parallel cores were taken in August 1979 at two sampling sites in Lake Lucerne (Fig. 1) with the gravity corer of Ambühl \& Bührer(1975) which was equipped with the two half-tubes used by Staub (1977). These sampling tubes allowed us to cut the fresh core into two halves (preparation technique described by Staub 1974), and to see the structure of the sediment (Fig. 2a and b).

Subsamples were taken at $1 \mathrm{~cm}$ intervals from 1 to $10 \mathrm{~cm}$, at $2 \mathrm{~cm}$ intervals from 10 to $20 \mathrm{~cm}$, and at $5 \mathrm{~cm}$ intervals from 20 to $40 \mathrm{~cm}$ of each core. The subsamples were dried for 2 weeks at $50^{\circ} \mathrm{C}$, and pulverized after weighing with a mechanic agate mortar. This powder was prepared for $\mathrm{Pb}-210$ analysis.

$\mathrm{Pb}-210$ was assayed by measuring the $\mathrm{Po}-210$ content of each subsample. Po-210 is the granddaughter of $\mathrm{Pb}-210$ and we assumed secular equilibrium between the two isotopes. The Po-210 was extracted using a slightly modified version of the distillation technique of Eakins \& Morrison (1978, see Evans 1980). After distillation the Po-210 was deposited on silver discs and counted in an alpha spectrometer (Canberra) on $300 \mathrm{~mm}^{2}$ surface carrier detectors. The isotope Po-208, produced in the McGill University (Montreal) cyclotron, by irradiation of bismuth foil, was added to the dry sediments prior to distillation as a yield indicator to measure the efficiency with which the Po-210 was extracted and plated. Recovery averaged $71 \%(\mathrm{n}=$ $117,2 \sigma= \pm 21 \%$ ). Our modification to Eakins \& Morrison's method involved removing nitric acid from the plating solution by drying at about $60^{\circ} \mathrm{C}$ rather than boiling with concentrated $\mathrm{HCl}$. This

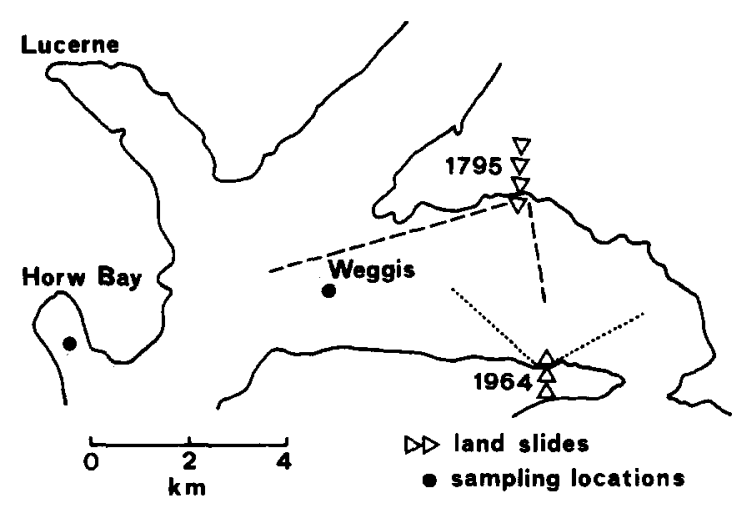

Fig. I. Lake Lucerne with sampling locations and landslides. 


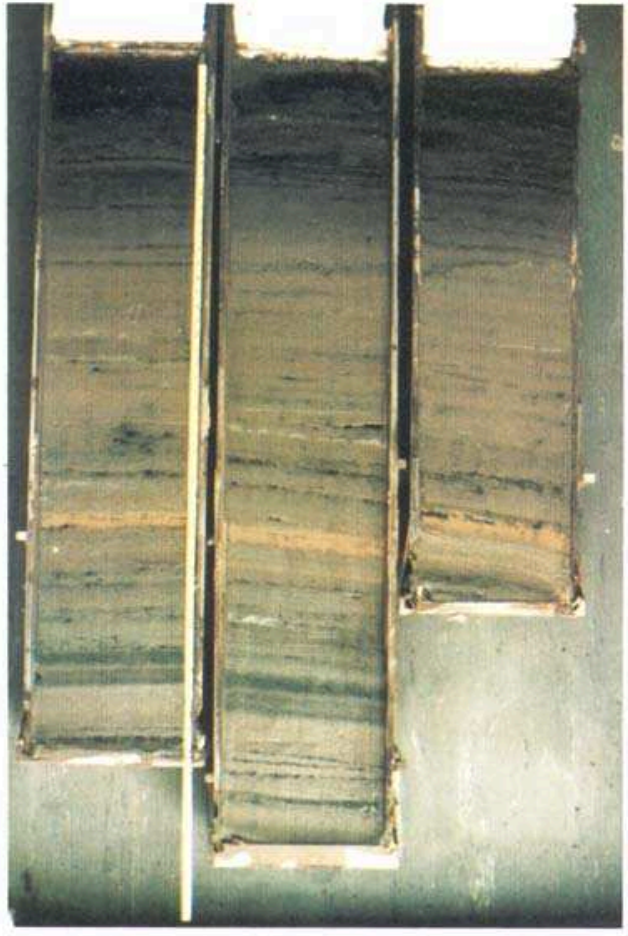

(a)

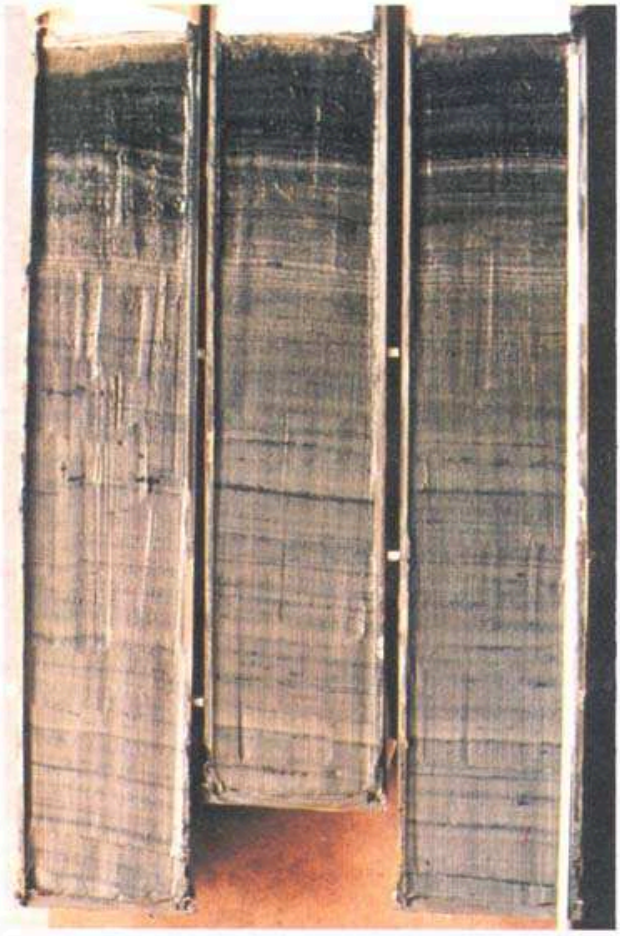

(b)

Fig. 2. Triplicate cores from Weggis (a) and Horw Bay (b) in Lake Lucerne. The Weggis cores are more consistent and the landslide marker is visible as a yellowish layer in the depth of approximately $33 \mathrm{~cm}$. The Horw Bay cores are softer and characterized by a sandy layer of allochthonous origin in the depth of approximately $6-7 \mathrm{~cm}$, and by some varves between 7 and $17 \mathrm{~cm}$.

makes the method less time consuming, yet there is no significant reduction in recovery of the polonium.

Cylindrical sediment traps (height $50 \mathrm{~cm}$, diameter $14 \mathrm{~cm}$ ) were set in $1969 / 70$ at the Horw Bay station in order to measure sedimentation rates at biweekly intervals for one year (Bloesch 1974, 1977).

Sediment accumulation rates based on $\mathrm{Pb}-210$ concentrations were calculated in the manner outlined in Evans \& Rigler (1980). At the Weggis sampling station, the landslide of 1795 provided a time marker (Fig. 1), and sediment accumulation rate predicted by this marker was calculated by dividing the total mass of dry sediment per unit area* above the marker by 184 years. Both calculation methods make the assumption of constant rate of sedimentation through time which, however, is not absolutely correct, because of short-term changes in climate and long-term changes in eutrophication (Staub 1981).

* Dry sediment concentration, $\mathrm{C}_{\mathrm{DW}}$, is given as

$$
\begin{aligned}
& \mathrm{C}_{\mathrm{DW}}=\frac{\mathrm{dry} \text { weight of sediment }[\mathrm{g}]}{\text { volume of total fresh sediment }\left[\mathrm{cm}^{3}\right]} \\
& =\frac{\text { dry weight }[\mathrm{g}]}{\text { water content }[\mathrm{g}] \frac{\mathrm{l}}{\rho_{\mathrm{H}_{2} \mathrm{O}}}\left[\frac{\mathrm{cm}^{3}}{\mathrm{~g}}\right]+\text { dry weight }[\mathrm{g}] \frac{\mathrm{I}}{\rho_{\mathrm{DW}}}\left[\frac{\mathrm{cm}^{3}}{\mathrm{~g}}\right]} \\
& =(1-\phi) \rho_{\mathrm{DW}} \\
& \phi \quad=\text { porosity }=\frac{\text { volume of pore water }\left[\mathrm{cm}^{3}\right]}{\text { volume of total fresh sediment }\left[\mathrm{cm}^{3}\right]} \\
& \rho_{\mathrm{H}_{i} \mathrm{O}}=\text { specific weight of pore water }=1 \mathrm{~g} \mathrm{~cm}^{-3} \\
& \rho_{\mathrm{DW}_{\text {sed }}}=\text { specific weight of dry sediment }=2.65 \mathrm{~g} \mathrm{~cm}^{-3} \text { (Vomocil 1965) }
\end{aligned}
$$



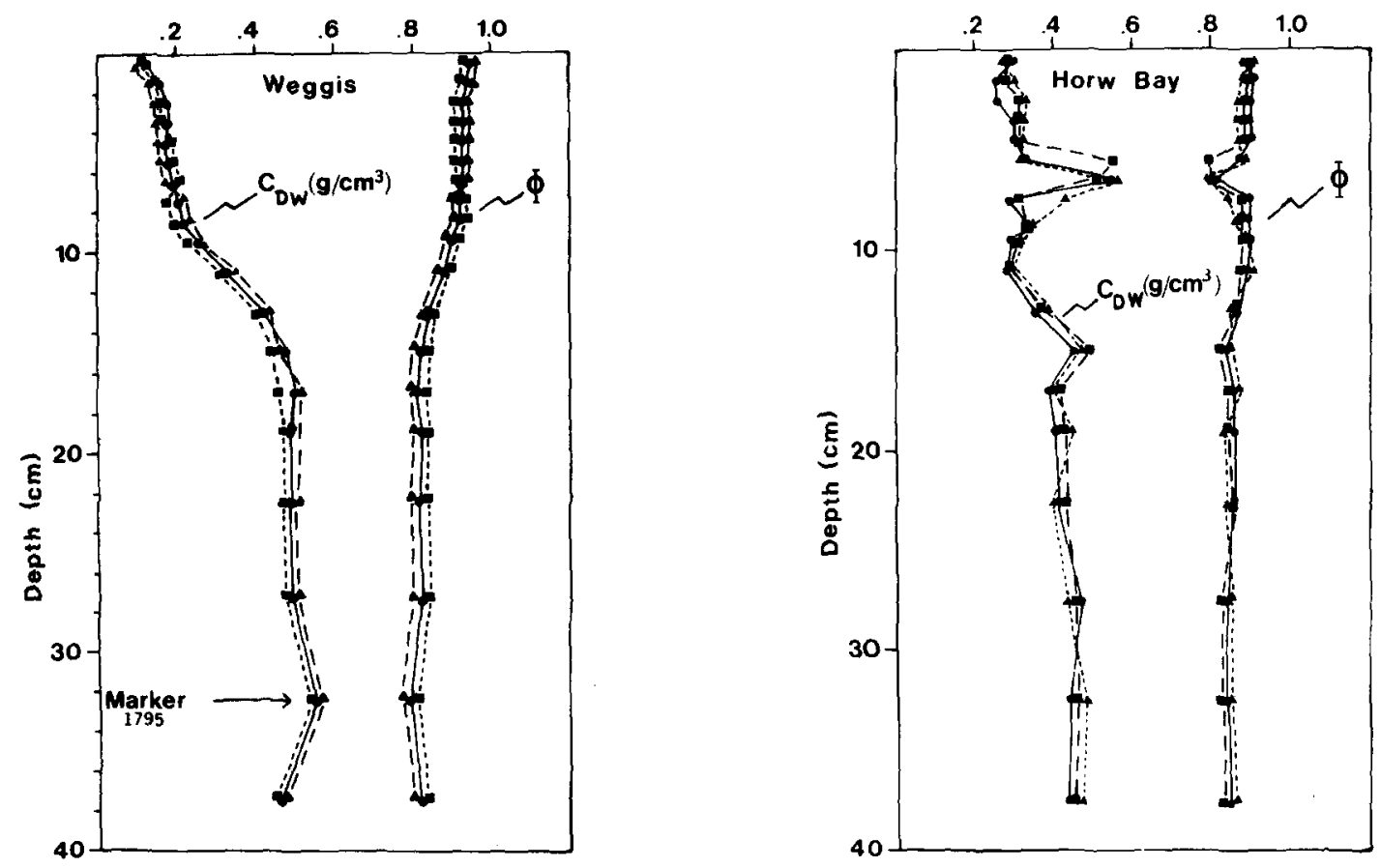

Fig. 3. Porosity $(\phi)$ and dry sediment concentration $\left(\mathrm{C}_{\mathrm{DW}}\right)$ in the Weggis cores (a) and Horw Bay cores (b) of Lake Lucerne. $\bullet$ - core 1 and $A,-$ core 2 and $B, 4-$ core 3 and $C$.
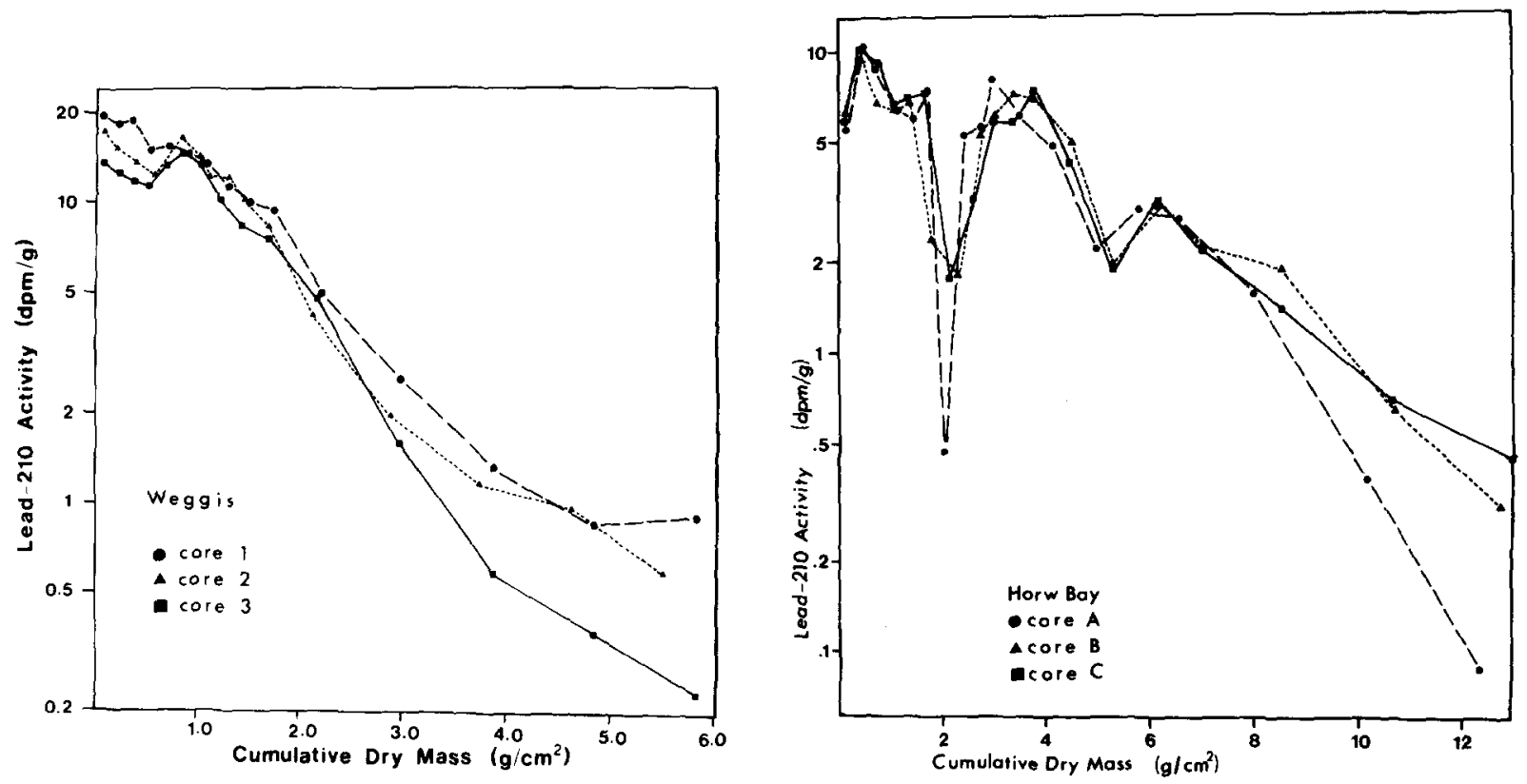

Fig. 4. Lead-210 activity profiles in the Weggis cores (a) and Horw Bay cores (b) of Lake Lucerne. 


\section{Results}

The porosity $\phi(=$ volume of pore water per volume of total fresh sediment) and the dry sediment concentration $\mathrm{C}_{\mathrm{DW}}(=\mathrm{dry}$ weight of sediment per volume of total fresh sediment $=(1-\phi) \rho_{\mathrm{DW}}$, $\rho=2.65$ [Vomocil 1965]) are shown in Fig. 3. Triplicate cores demonstrate good similarity, suggesting that the observed discontinuities represent real events in the lake's history rather than analytical errors. The landslide marker of 1795 at the depth of approximately $33 \mathrm{~cm}$ in the Weggis cores is clearly visible (see also Fig. 2a), and its dry weight concentration was distinctly higher than in the layers above and below $\left(0.631 \mathrm{~g} \mathrm{~cm}^{-3}\right.$ vs. $\left.0.474 \mathrm{~g} \mathrm{~cm}^{-3}\right)$, whereas the porosity was smaller $(0.762$ vs. 0.821$)$. In the cores of Horw Bay, a marked discontinuity at about $5-7 \mathrm{~cm}$ depth as well as some minor discontinuities can be detected.

The activity of $\mathrm{Pb}-210$ per gram dry weight vs. the cumulative dry weight $\left(C_{D W}\right) / \mathrm{cm}^{2}$ is given in a logarithmic scale in Fig. 4. The similarity in lead activity between triplicate cores is distinctly less than that for porosity and dry weight concentration (Fig. 3), which give rise to problems in calculating accumulation rates.

The calculated sediment accumulation rates and the sedimentation rates measured with the traps are compiled in Table 1. The significant differences will be discussed below. The raw data for cumulative dry weight $\left(\mathrm{C}_{\mathrm{DW}}\right)$ and $\mathrm{Pb}$-activity are given in $\mathrm{Ta}$ ble 2 .

Table 1 . Sediment accumulation rates (dry weight) calculated with the lead-210 method and on the basis of the landslide marker of 1795 (Weggis), and measured by sediment traps in 1969/70 (Horw Bay, Bloesch 1974). Values in $g$ dry wt. $\mathrm{m}^{-2} \mathrm{y}^{-1}$.

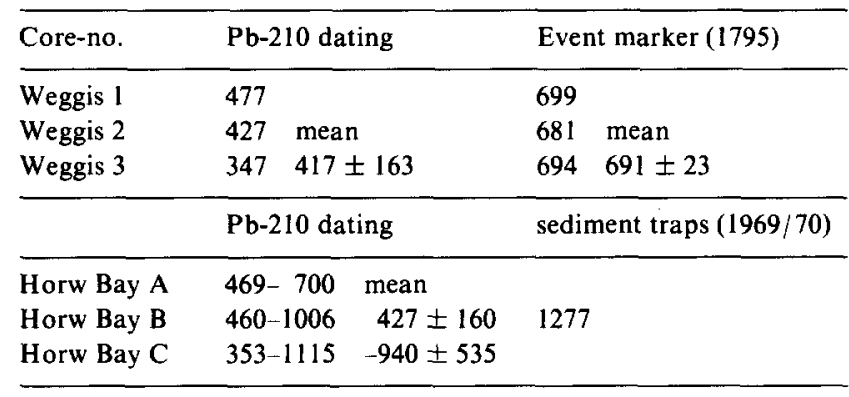

\section{Discussion}

From the results of Table 1 it is apparent that there is a systematic discrepancy between the lead210 dating method and the event marker dating method. The average accumulation for the three Weggis cores, from lead-210 dating, is $417 \mathrm{~g}$ dry wt. $\mathrm{m}^{-2} \mathrm{y}^{-1}$ related to $4-20 \mathrm{~cm}$. (The uppermost $4 \mathrm{~cm}$ are not considered because of deviation from a simple log-linear relationship, see Evans \& Rigler 1980.) The average accumulation from 0 to $33 \mathrm{~cm}$, or from 1795 to 1979 , respectively, calculated by the event marker method is $691 \mathrm{~g}$ dry wt. $\mathrm{m}^{-2} \mathrm{y}^{-1}$. To make the results fully comparable, we also have to subtract the upper $4 \mathrm{~cm}$ (about 5 years) in the marker method, since the yearly sediment layers are higher in this section (no compaction). This correction, however, reduces the rates only by $13-17 \mathrm{gdry}$ wt. $\mathrm{m}^{-2} \mathrm{y}^{-1}(2 \%)$.

In general, very little is known about landslide deposition in lakes and it is possible that the use of slide markers may over-estimate subsequent (lake wide) sediment accumulations. The base of such horizons may occur deeper than expected, in sediment core profiles. In explanation of this, we may imagine that a dense and compact clay-slide enters the water and moves down the slope of the lake bed as an entrained flow, associated with strong turbidity currents which erode and re-suspend the flocculent surface material.

Since our sampling site is located peripheral to such an affected area (Fig. 1), it seems likely that our sediment core profiles would remain almost unaffected by erosion from slide-induced turbidity currents. At our site, it is probable that the lake bed received only the settlement of fine particles associated with the tail of the entrained flow (Fig. 2a), and this is supported by the lack of variation between our triplicate cores (Fig. 3a, Table 1). This lack of variation is not typical of sites where slide induced erosion has occurred close to, or within, the path of the entrained flow (Swan 1979, Fig. 12).

Despite the lack of local scouring, however, it is possible that an advancing pressure wave, associated with the entrained flow and turbidity currents, may have re-suspended the flocculent surface sediments at some distance away from the direct path of the slide. These would have resettled after the slide. It is possible for, perhaps, the upper $5 \mathrm{~cm}$ of fresh material to have been resuspended in 1795 and later 
Table 2. Depth, cumulative dry mass $\left(C_{D W}\right)$, total lead-210 activity $\left(A_{t}\right)$, and unsupported lead-210 activity (A) for each of three replicate cores from the Weggis and Horw regions of Lake Lucerne.

\begin{tabular}{|c|c|c|c|c|c|c|c|c|c|}
\hline \multirow[t]{2}{*}{ Depth } & \multicolumn{3}{|c|}{ Weggis core 1} & \multicolumn{3}{|c|}{ Weggis core 2} & \multicolumn{3}{|c|}{ Weggis core 3} \\
\hline & $\mathrm{C}_{\mathrm{DW}}$ & $A_{t}$ & $\mathrm{~A}$ & $\mathrm{C}_{\mathrm{DW}}$ & $A_{t}$ & A & $\mathrm{C}_{\mathrm{DW}}$ & $A_{t}$ & A \\
\hline $0-1$ & 0.07 & 22.46 & 19.51 & 0.06 & 20.48 & 17.46 & 0.06 & 16.76 & 13.83 \\
\hline $1-2$ & 0.21 & 21.49 & 18.54 & 0.21 & 18.22 & 15.20 & 0.20 & 15.58 & 12.65 \\
\hline $2-3$ & 0.38 & 22.02 & 19.07 & 0.38 & 16.71 & 13.69 & 0.35 & 14.96 & 12.04 \\
\hline $3-4$ & 0.55 & 18.00 & 15.05 & 0.55 & 15.43 & 12.41 & 0.50 & 14.54 & 11.61 \\
\hline $4-5$ & 0.73 & 18.34 & 15.39 & 0.72 & 19.68 & 16.67 & 0.66 & 16.47 & 13.55 \\
\hline $5-6$ & 0.91 & 17.52 & 14.57 & 0.90 & 17.09 & 14.07 & 0.82 & 17.84 & 14.92 \\
\hline $6-7$ & 1.10 & 16.36 & 13.41 & 1.09 & 15.29 & 12.27 & 1.00 & 16.47 & 13.55 \\
\hline $7-8$ & 1.30 & 14.13 & 11.18 & 1.28 & 15.06 & 12.04 & 1.20 & 13.35 & 10.43 \\
\hline $8-9$ & 1.51 & 12.97 & 10.02 & 1.46 & 13.31 & 10.29 & 1.42 & 11.61 & 8.68 \\
\hline $9-10$ & 1.75 & 12.34 & 9.39 & 1.68 & 11.47 & 8.45 & 1.66 & 10.67 & 7.74 \\
\hline $10-12$ & 2.21 & 7.94 & 4.99 & 2.12 & 7.22 & 4.20 & 2.15 & 7.84 & 4.91 \\
\hline $12-14$ & 2.96 & 5.57 & 2.61 & 2.87 & 5.00 & 1.98 & 2.93 & 4.58 & 1.65 \\
\hline $14-16$ & 3.86 & 4.26 & 1.31 & 3.73 & 4.20 & 1.18 & 3.85 & 3.45 & 0.52 \\
\hline $16-18$ & 4.84 & 3.82 & 0.87 & 4.63 & 4.01 & 0.99 & 4.83 & 3.30 & 0.38 \\
\hline $18-20$ & 5.83 & 3.87 & 0.90 & 5.58 & 3.63 & 0.61 & 5.81 & 3.16 & 0.24 \\
\hline $20-25$ & 7.55 & 3.00 & 0.05 & 7.29 & 3.12 & & 7.51 & 2.88 & \\
\hline $25-30$ & 9.98 & 2.95 & & 9.71 & 3.02 & & 9.94 & 2.93 & \\
\hline $30-35$ & 12.58 & 2.71 & & 12.26 & 2.78 & & 12.51 & 2.50 & \\
\hline $35-40$ & 15.16 & 3.10 & & 14.77 & 3.12 & & 14.98 & 3.16 & \\
\hline Marker & 12.86 & 2.56 & & 12.52 & 1.79 & & 12.77 & 1.84 & \\
\hline \multirow[t]{2}{*}{ Depth } & \multicolumn{3}{|c|}{ Horw core A } & \multicolumn{3}{|c|}{ Horw core $B$} & \multicolumn{3}{|c|}{ Horw core $\mathrm{C}$} \\
\hline & $\mathrm{C}_{\mathrm{DW}}$ & $A_{1}$ & A & $C_{D W}$ & $A_{t}$ & A & $\mathrm{C}_{\mathrm{DW}}$ & $A_{t}$ & $\mathbf{A}$ \\
\hline $0-1$ & 0.15 & 7.79 & 5.52 & 0.15 & 8.40 & 6.37 & 0.14 & 8.10 & 5.88 \\
\hline $1-2$ & 0.43 & 12.60 & 10.34 & 0.43 & 11.52 & 9.49 & 0.43 & 12.59 & 10.37 \\
\hline $2-3$ & 0.69 & 11.14 & 8.87 & 0.73 & 8.78 & 6.75 & 0.74 & 11.49 & 9.27 \\
\hline $3-4$ & 0.97 & 8.68 & 6.42 & 1.05 & 8.59 & 6.56 & 1.06 & 8.92 & 6.70 \\
\hline $4-5$ & 1.26 & 8.31 & 6.04 & 1.37 & 8.83 & 6.80 & 1.38 & 9.09 & 6.87 \\
\hline $5-6$ & 1.58 & 9.82 & 7.55 & 1.80 & 4.44 & 2.40 & 1.70 & 9.62 & 7.40 \\
\hline $6-7$ & 2.02 & 2.74 & 0.47 & 2.33 & 3.87 & 1.84 & 2.14 & 3.97 & 1.74 \\
\hline $7-8$ & 2.44 & 7.60 & 5.33 & 2.75 & 7.27 & 5.24 & 2.64 & 5.42 & 3.20 \\
\hline $8-9$ & 2.75 & 7.88 & 5.61 & 3.07 & 8.17 & 6.14 & 3.02 & 8.10 & 5.88 \\
\hline $9-10$ & 3.07 & 10.43 & 8.17 & 3.40 & 9.25 & 7.22 & 3.35 & 8.05 & 5.83 \\
\hline $10-12$ & 3.51 & 8.40 & 6.14 & 3.84 & 9.02 & 6.99 & 3.80 & 9.74 & 7.52 \\
\hline $12-14$ & 4.16 & 7.13 & 4.86 & 4.49 & 7.08 & 5.05 & 4.49 & 6.41 & 4.19 \\
\hline $14-16$ & 4.97 & 4.48 & 2.22 & 5.34 & 4.01 & 1.98 & .5 .35 & 4.14 & 1.92 \\
\hline $16-18$ & 5.81 & 5.24 & 2.97 & 6.24 & 5.14 & 3.11 & 6.23 & 5.54 & 3.32 \\
\hline $18-20$ & 6.60 & 5.10 & 2.83 & 7.09 & 4.30 & 2.27 & 7.07 & 4.43 & 2.21 \\
\hline $20-25$ & 8.03 & 3.82 & 1.56 & 8.56 & 3.96 & 1.93 & 8.53 & 3.61 & 1.39 \\
\hline $25-30$ & 10.18 & 2.64 & 0.38 & 10.70 & 2.69 & 0.66 & 10.67 & 2.92 & 0.70 \\
\hline $30-35$ & 12.45 & 2.36 & 0.09 & 12.96 & 2.36 & 0.33 & 12.92 & 2.68 & 0.46 \\
\hline $35-40$ & 14.68 & 2.27 & 0.00 & 15.23 & 2.03 & 0.00 & 15.18 & 2.22 & 0.00 \\
\hline
\end{tabular}

redeposited over the slide material. If this was, later, compacted to $3 \mathrm{~cm}$ between 1795 and 1979 , the apparent sedimentation rates would be reduced by approximately $90 \mathrm{~g}$ dry wt. $\mathrm{m}^{-2} \mathrm{y}^{-1}(13 \%)$. If this type of correction is used to make this dating method coincide with the lead- 210 method, a sediment layer of $15-20 \mathrm{~cm}$ would have to have been displaced during the slide event (corresponding to a compacted layer of $8-13 \mathrm{~cm}$ in recovered cores). On the basis of the visible structures in the cores, however, this seems to be rather unrealistic.

Thus, if corrections are based on the more tenable 
assumptions, based on core characteristics, the marker accumulation rates can be modified by about $110 \mathrm{~g}$ dry wt. $\mathrm{m}^{-2} \mathrm{y}^{-1}(16 \%)$; and this may be considered as falling within the error range or accuracy of the method (rather than being a significant overestimation). In any case, a considerable difference between the two dating methods remains.

The crucial problem of the lead-210 dating method is the calculation of the regression in the exponential part of the lead-activity curve. Since the ratios of lead-210 surface activity to supported 'background' activity in the Weggis cores are low, when compared with cores from other lakes (Evans 1980; Evans \& Rigler 1980; Robbins 1978), small changes in the estimate of supported lead- 210 activity give rise to large changes in predicted sediment accumulation rates. This is evident in the variety of results from triplicate cores (Table 1) which did not show the same consistency as the original data (Fig. 4 vs. Fig. 3), although counting errors do not exceed $\pm 10 \%$.

Based on the fact that the lowest activity in all three Weggis cores was found in the marker layer, which apparently depresses the background level in the $30-35 \mathrm{~cm}$ section (see Table 2), we have tested a hypothesis of allochthonous dilution of the lead-210 concentration. We know of the important influence of inorganic river inputs in Lake Lucerne (Bloesch 1974; Staub 1981) and we can conclude, from our lead-210 background measurements, that the rock material of the drainage area is much older than the lake sediments at $30 \mathrm{~cm}$ depth, because of its lower activity. The resulting dilution effect would then be proportional to the river discharge and would be greatest at the surface where lead- 210 activity is highest. In addition, this dilution in the upper $10 \mathrm{~cm}$ or so would have been further enhanced by the increasing autochthonous sediment input of organic matter and biogenic calcite precipitation, both associated with progressive eutrophication since the 1950s (Staub 1981). The dilution effect may also account for the underestimation of sediment accumulation rates, since the measured lead-210 activity appears to be older than effective ages of layers. However, several attempts to correct for this dilution failed, including a nonlinear approach suggested by Appleby et al. (1979), unless the background activity was lowered drastically beyond the marker level. In conclusion, the lack of agreement with the marker event method seems to be most probably explained by too high background activities of lead-210.

It is possible, although we have found similar low activities at the depth of $20-40 \mathrm{~cm}$ in each core (Table 2), that we have not yet reached background levels at $40 \mathrm{~cm}$ and that therefore the estimates of background activity are consistently too high, resulting in the apparent underestimation of the actual accumulation rate. In addition, it is also possible that not all assumptions on which the lead-210 dating method is based (Evans \& Rigler 1980) are totally fulfilled in our case. It might be argued that at the depth of the cores (below $25 \mathrm{~cm}$ ) $\mathrm{Pb}-210$ is not in equilibrium with $\mathrm{Ra}-226$ and that the background values include some small sources of unsupported lead-210. Reduction of the background estimate by about $50 \%$ is necessary to bring the lead-210 dating accumulation rates into line with the event marker accumulation rates. However, it should be noted that the background required to give this consistency is different for each core, varying between 0 and $1.4 \mathrm{dpm} \mathrm{g}^{-1}$.

The log-linear approach in calculating sedimentation rates from lead- 210 profiles becomes much more problematic when natural discontinuities are recorded in the cores, as was the case in those of Horw Bay (Figs. 2b, 3b and 4b). Two possible calculations using the whole activity profile, and assuming supported lead-210 activity to be zero, yielded mean accumulation rates of 1720 and $3100 \mathrm{~g}$ dry wt. $\mathrm{m}^{-2} \mathrm{y}^{-1}$, respectively. However, the most reasonable assumptions taking the $9-16 \mathrm{~cm}, 16-35$ $\mathrm{cm}$, or the combined $9-35 \mathrm{~cm}$ section, resulted in accumulation rates of between 353 and $1115 \mathrm{~g}$ dry wt. $\mathrm{m}^{-2} \mathrm{y}^{-1}$, with a great variability even between the triplicate cores (Table 1).

The reference accumulation rate of $1277 \mathrm{~g}$ dry wt. $\mathrm{m}^{-2} \mathrm{y}^{-1}$ measured by traps (Bloesch 1974) exceeds these values considerably. Although we have no precise information about either mineralization in the traps or lake bottom resuspension, neither process is thought to be dominant in Horw Bay (near bottom temperatures of $4-6^{\circ} \mathrm{C}$, depth of $62 \mathrm{~m}$ ). Thus, the sedimentation trap rates should be a fairly good reference, and we can assume that the lead210 dating method underestimates the sedimentation rates because of the same reasons which apply at the Weggis site. If we assume an underestimation of about $40 \%$, which resulted from the comparison with the slide marker method in the Weggis cores, 
the mean sediment accumulation rate calculated by the lead-210 method can be corrected to $1313 \mathrm{~g}$ dry wt. $\mathrm{m}^{-2} \mathrm{y}^{-1}$; this is in good agreement with the trap sedimentation rate.

\section{Summary and conclusions}

We have cross-checked three different methods for measuring sedimentation rates: a natural landslide marker, lead-210 dating, and sedimentation traps. Each method has well-known sources of errors which, on the basis of published information, are thought to be usually limited to less than $\pm 20 \%$. In our study we could find agreement neither between marker and lead dating nor between trap and lead dating. The lead method yielded significant lower sediment accumulation rates. These discrepancies have been attributed to an unusual high background activity which may have caused a major underestimation, using the lead-210 method. It is also possible that allochthonous inorganic material or biogenic calcite precipitation may have influenced lead-activity profiles by dilution. We therefore conclude that the lead-dating method may fail in lakes with high allochthonous input and/or accelerated eutrophication.

Further research is required to find methods which provide reliable and accurate sediment accumulation rates.

\section{References}

Ambühl, H. \& Bührer, H., 1975. Zur Technik der Entnahme ungestörter Grossproben von Seesedimenten: ein verbessertes Bohrlot. Schweiz. Z. Hydrol. 37: 175-186.

Appleby, P. G., Oldfield, F., Thompson, R., Huttunen, P. \& Tolonen, K., 1979. ${ }^{210} \mathrm{~Pb}$ dating of annually laminated sediments from Finland. Nature 280: 53-55.

Bloesch, J., 1974. Sedimentation und Phosphorhaushalt im Vierwaldstättersee (Horwer Bucht) und im Rotsee. Schweiz. Z. Hydrol, 36: 71-186.

Bloesch, J., 1977. Sedimentation rates and sediment cores in two Swiss lakes of different trophic state. In: Golterman, H. L. (Ed.) Interactions between Sediments and Freshwater, pp. 65-71. Proc. Int. Symp. Amsterdam, 6-10 September 1976.

Bloesch, J. \& Burns, N, M., 1980. A critical review of sedimentation trap technique. Schweiz. Z. Hydrol. 42: 15-55.

Dillon, P. J. \& Rigler, F. H., 1974. A test of a simple nutrient budget model predicting the phosphorus concentration in lake water. J. Fish. Res. Bd Can. 31: 1771-1778.

Eakins, J. D. \& Morrison, R. I., 1978. A new procedure for the determination of lead- 210 in lake and marine sediments. Int. J. appl. Radiat. Isotopes 29: 531-536.
Evans, R. D., 1980. Measurement of sediment accumulation and phosphorus retention using lead-210 dating. Ph.D. thesis, McGill University, Montreal. 169 pp.

Evans, R. D. \& Rigler, F. H., 1980. The measurement of whole lake sediment accumulation and phosphorus retention using lead-210 dating. Can. J. Fish. aquat. Sci. 37: 817-822.

Fuhs, G., 1973. Improved device for the collection of sedimenting matter. Limnol. Oceanogr. 18: 989-993.

Gardner, W. D., 1980. Sediment trap dynamics and calibration. A laboratory evaluation. J. mar. Res. 38: 17-39.

Gardner, W. D., 1980. Field assessment of sediment traps. J. mar. Res. 38: 41-52.

Hargrave, B. T. \& Burns, N. M., 1979. Assessment of sediment trap collection efficiency. Limnol. Oceanogr. 24: 1124-1135.

Imboden, D. M. \& Gächter, R., 1979. The impact of physical processes on the trophic state of a lake. In: Ravera, O. (Ed.) Biological Aspects of Freshwater Pollution, pp. 93-110. Pergamon Press, Oxford.

Imboden, D. M.\& Lerman, A., 1978. Chemical models of lakes. In: Lerman, A. (Ed.) Lakes: Chemistry, Geology, Physics, pp. 341-356. Springer-Verlag, New York.

Kipphut, G. W., 1979. An investigation of sedimentary processes in lakes. Ph.D. thesis, Columbia University, 1978. $180 \mathrm{pp}$.

Nicholls, K. H., 1976. The comparative limnology of Harp and Jerry Lakes, adjacent cottaged and uncottaged lakes on Ontario's Precambrian Shield. Ontario Ministry of the Environment Report. 82 pp.

Pennington, W., 1974. Seston and sediment formation in five Lake District lakes. J. Ecol. 62: 215-251.

Ravera, O. \& Viola, M., 1977. Sedimentation rate in a basin (Agno) of Lake Lugano. In: Golterman, H. L. (Ed.) Interactions between Sediments and Freshwater, pp. 174-178. Proc. Int. Symp. Amsterdam, 6-10 September 1976.

Robbins, J. A., 1978. Geochemical and geophysical applications of radioactive lead. In: Nriagu, J. (Ed.), pp. 285-393. The Biogeochemistry of Lead in the Environment. Elsevier/ North Holland, Amsterdam.

Serruya, C., 1977. Rates of sedimentation and resuspension in Lake Kinneret. In: Golterman, H. L. (Ed.) Interactions between Sediments and Freshwater, pp. 48-56. Proc. Int. Symp. Amsterdam, 6-10 September 1976.

Staub, E. A., 1974. Biologisch-stratigraphische Untersuchungen an jungen Sedimenten des Vierwaldstättersees. M.Sc. thesis, ETH Zürich. 65 pp.

Staub, E. A., 1977. Stratigraphy of diatoms and chlorophyll derivatives in the uppermost sediment of a Swiss lake. In: Golterman, H. L. (Ed.) Interactions between Sediments and Freshwater, pp. 161-164. Proc. Int. Symp. Amsterdam, 6-10 September 1976

Staub, E. A., 1981. Diagenese im rezenten Sediment des Vierwaldstättersees und ihre Veränderung durch die Eutrophierung: Tiefenprofile biologisch-chemischer Parameter im Sediment und Porenwasser. Ph.D. thesis, ETH Zürich. 224 pp.

Swan, D., 1979. Large submarine landslide, Kitimat Arm, B. C. In: First Canadian Conference on Marine Geotechnical Engineering, Calgary, Alberta, April 1979. pp. 131-139.

Vollenweider, R. A., 1975. Input-output models, with special reference to the phosphorus loading concept in limnology. Schweiz. Z. Hydrol. 37: 53-84.

Vomocil, J. A., 1965. Porosity. Agronomy 9: 299-314. 